\title{
La conceptualización metafórica del eufemismo en epitafios
}

\author{
Metaphorical conceptualization of euphemism in epitaphs
}

\section{Eliecer Crespo Fernández.}

\author{
Universidad de Alicante, Facultad de Filosofía y Letras (Edificio B) \\ Apartado de Correos 99, Campus de San Vicente del Raspeig, Alicante E- 03080, España, \\ e-mail: eliecer.crespo@ua.es
}

Dado que el epitafio constituye un caldo de cultivo para la evasión eufemística del tabú de la muerte, el objetivo del presente artículo es analizar el lenguaje eufemístico en una muestra de epitafios recogidos en el cementerio de Albacete (España). Considerando lo habitual del lenguaje figurado en el eufemismo, este trabajo se basa en el modelo de la metáfora conceptual propuesto por Lakoff y Johnson para dar cuenta de las diferentes conceptualizaciones metafóricas del eufemismo presente en las inscripciones funerarias del corpus y de su evolución diacrónica.

Palabras clave: eufemismo, tabú de la muerte, epitafio, metáfora conceptual.

As epitaphs constitute a breeding ground for death-related euphemism, the aim of this paper is to explore the euphemistic language on epitaphs excerpted from the cemetery of Albacete (Spain). Given the pervasiveness of metaphor in euphemisms, the present study proceeds to trace an account of the different conceptual metaphors aimed at substituting death-related notions in epitaphs within the framework of the Conceptual Metaphor Theory initiated by Lakoff and Johnson. It also aims reveal the main characteristics of the conceptualization of death from a diachronic perspective.

Key words: euphemism, death taboo, epitaph, conceptual metaphor.

\section{INTRODUCCIÓN}

La muerte es el tabú ${ }^{1}$ más universal y el que más ha resistido a los efectos corrosivos del paso del tiempo. Su vigencia en la época actual, momento que paradójicamente es testigo de la desaparición de numerosas prohibiciones y de la relajación de otrora represiones públicas y privadas, prueba la incapacidad del ser humano de convivir con la muerte, ni siquiera de llegar a entender a ese juez insobornable ante el que todos, tarde o temprano, hemos de rendir cuentas. Esta indefensión del género humano ante

\footnotetext{
${ }^{1}$ Siguiendo a Moreno Fernández (1998: 201), tabú se define como 'la prohibición de ciertas acciones u objetos basada bien en razones religiosas, bien en otros prejuicios, convenciones o actitudes sociales', mientras que el tabú lingüístico es 'la palabra cuyo uso debe evitarse, generalmente por motivos sociales, políticos, sexuales o religiosos'.
} 
la muerte es puesta de manifiesto por García-Sabell (1999: 15): "Poseemos, en cierto sentido, la muerte, pero ella nos posee de forma absoluta. Por eso cuando creemos que ya la entendemos, ella, aguda, huye de nuestras búsquedas". La muerte constituye pues un tabú ciertamente especial en el que interdicciones de naturaleza psicológica y social coexisten como, me atrevería a decir, en ningún otro. Tal vez por ello, la inmensa mayoría de las sociedades y culturas intentan buscarle una justificación, un lugar en el que pueda encajar dentro de los ritos humanos y, cómo no, pretenden abordarla en el plano lingüístico, lo cual no es tarea fácil.

Considerando los factores que inciden en el tratamiento público de la muerte (el respeto al difunto y a sus familiares, la cortesía esperable ante un hecho luctuoso, supersticiones, miedos, etc.), los usuarios de la lengua tratan por lo general de evitar la referencia directa a ella. Así, no es de extrañar que se recurra a la sustitución léxica de aquellas voces que la designan de manera considerada inapropiada en una determinada situación comunicativa. En este sentido, el eufemismo -proceso por el que se sustituye una palabra o expresión cargada con las connotaciones negativas del concepto tabú, y que resulta inadecuada $u$ ofensiva en un determinado contexto comunicativo, por otra libre de tales connotaciones- resulta imprescindible en textos en los que la referencia a la muerte se antoja inevitable. En este sentido, el epitafio (del griego epi 'sobre' y taphos 'tumba'), 'inscripción que se pone, o se supone puesta, sobre un sepulcro o en la lápida o lámina colocada junto al enterramiento', según el DRAE, constituye un verdadero caldo de cultivo para la proliferación de sustituciones léxicas evasivas de tabúes lingüísticos que atañen a la muerte.

Pese a lo común del eufemismo en las inscripciones funerarias, el fenómeno no ha recibido, en mi opinión, el tratamiento que merece como mecanismo de huida del tabú de la muerte en estos textos; de hecho, hasta la fecha no ha aparecido un trabajo que aborde exclusivamente el eufemismo en epitafios. Con respecto al tabú de la muerte, generalmente el fenómeno eufemístico se ha estudiado de manera tangencial como parte de tratados más generalistas de corte cultural y antropológico más que lingüístico (Carandell 1975; Barley 2000). Otros estudios se han dedicado a examinar las características del lenguaje fúnebre en las esquelas, tanto en el ámbito hispánico (Belmonte 1996; Hernando 2001) como anglosajón (Gross 1985; Hume 2000). Este estado de la cuestión viene a justificar el principal objetivo del presente artículo, que no es otro que analizar el lenguaje eufemístico utilizado en la referencia a la muerte en epitafios.

Dado que la metáfora constituye un importante recurso eufemístico (Casas Gómez 1986: 217-218; Crespo Fernández 2006b y 2007: 95-103) y un modo habitual de abordar la muerte (Chamizo Domínguez y Sánchez Benedito 2000: 75-77; Barley 2000: 197-232 y Sexton 1997), este trabajo se centra en la categorización conceptual de las metáforas eufemísticas empleadas para evadir los tabúes lingüísticos relacionados con la muerte según el modelo de la metáfora conceptual iniciado por Lakoff y Johnson (1980), modelo aplicado con anterioridad al tema del lenguaje figurado en la designación de la muerte (Marín Arrese 1996; Sexton 1997 y Bultnick 1998) y, de manera más específica, a la metáfora como recurso eufemístico en esquelas de periódicos irlandeses (Crespo Fernández 2006a). Para tal fin, después de presentar el corpus de epitafios manejado, la metodología empleada y el marco teórico en el que se basa la investigación, analizaré las categorizaciones conceptuales en las que se agrupan los sustitutos eufemísticos de naturaleza metafórica observados en el corpus 
y daré cuenta de lo significativo de su evolución diacrónica. Finalmente, ofreceré los resultados y reflexiones que se desprenden del análisis efectuado.

\section{CORPUS y METODOLOGÍA}

En toda investigación de naturaleza empírica es preciso tener en cuenta la naturaleza de los fenómenos lingüísticos en los que se basa como factor determinante en la elección del corpus. En este sentido, la opción por un corpus de epitafios para el presente trabajo se debe al hecho de que este tipo de texto, en tanto inscripción funeraria, no puede evitar la referencia, más o menos velada, sentimental o poética, al tabú de la muerte y, por tanto, se antoja como un auténtico caldo de cultivo para el eufemismo. Así, la presente investigación se basa en un corpus que consta de 1253 inscripciones de fosas y nichos del cementerio "Ntra. Señora de la Virgen de los Llanos" de la localidad de Albacete, capital de la provincia del mismo nombre, de unos 150.000 habitantes, situada en el sureste de España ${ }^{2}$. Este cementerio, construido en 1878 , mide aproximadamente $400.000 \mathrm{~m}^{2}$ y en la actualidad el número de enterrados ronda los $140.000^{3}$. Aunque la totalidad de epitafios consultados dista sobremanera de abarcar una mayoría de los existentes, considero que el número manejado -poco menos del $10 \%$ de la totalidad-constituye una muestra representativa de la naturaleza de las inscripciones en el cementerio de Albacete; además, su análisis arrojaría datos fácilmente extrapolables al resto, lo que nos permitiría extraer conclusiones válidas sobre el eufemismo metafórico presente en los epitafios.

En la recogida de datos para el presente trabajo no me he limitado a un periodo concreto, pues las lápidas consultadas abarcan desde el último tercio del siglo XIX hasta nuestros días. Esta visión de conjunto aportará datos sin duda reveladores no sólo del eufemismo conceptual empleado en la designación del tabú de la muerte, sino también de su evolución diacrónica. La metodología empleada responde, por tanto, a la necesidad de recoger un número lo suficientemente amplio de epitafios de distintas épocas. Así, recopilé inscripciones en distintas zonas del cementerio, anotando las sustituciones eufemísticas presentes en lápidas de nichos y fosas. Para ello, dividí el cementerio en cuatro zonas según la época de las inhumaciones, zonas que presento a continuación con el número de epitafios entre paréntesis:

- Zona 1. Ultimo cuarto del siglo XIX hasta 1930 (370).

- Zona 2. Décadas de 1930, 1940 y 1950 (244).

- Zona 3. Décadas de 1960 y 1970 (327).

- Zona 4. Ultimas dos décadas del siglo XX hasta la actualidad (312).

\footnotetext{
${ }^{2}$ La elección de Albacete no es fruto del azar, pues se trata de una localidad que se considera paradigmática del avance urbano y cultural que tuvo lugar en España a partir de los años cincuenta en zonas fundamentalmente rurales. Así lo entiende también Belmonte (1998) en su trabajo sobre las esquelas, en el que la ciudad de Albacete sale a relucir asiduamente.

${ }^{3}$ El cementerio de Albacete constituye un ejemplo representativo de lo que Belmonte (1998: 88) denomina "cementerio ciudad": aquél típicamente urbano de galerías y nichos construido en un recinto cerrado con escasa vegetación y abundancia de construcciones artificiales.
} 
Cabe señalar que en estas zonas no he recogido únicamente aquellos epitafios más ricos en cuanto a la metaforización eufemística, sino que, a fin de obtener un panorama general del lenguaje figurado en la designación de la muerte, he prestado atención a todos los nichos existentes en galerías y pabellones concretos del cementerio que correspondían en su mayoría a las épocas arriba señaladas, a saber: nichos de las galerías de la Virgen de los Llanos y San José (zona 1); galerías de Ntra. Sra. del Carmen y Ntra. Sra. del Pilar (zona 2); pabellones de Ntra. Sra. del Rosario, San Luis y Ntra. Sra. de la Estrella (zona 3), y Pabellón Juan XIII (zona 4). Además de los nichos, he anotado también las inscripciones existentes en fosas, que he incluido en su zona correspondiente según la época de inhumación a fin de obtener resultados en diacronía válidos. Con el mismo objeto, he seguido igual procedimiento en aquellos epitafios más recientes con respecto al periodo en el que tuvieron lugar mayoritariamente los enterramientos hallados en las galerías indicadas. A fin de organizar la amplia variedad de eufemismos existentes, una vez recogidos, me centré en los sustitutos eufemísticos de naturaleza metafórica en referencia a la muerte y conceptos afines, que pasé a encuadrar en su correspondiente conceptualización eufemística de acuerdo con el modelo de la metáfora conceptual que paso a explicar brevemente a continuación.

\section{MARCo TEÓRICO: EL EUfEMISMO Y EL ENFOQUe COGNITIVO}

La base teórica en la que se sustenta el artículo se deriva del modelo de la metáfora conceptual, propuesto por Lakoff y Johnson en 1980 en su celebérrimo Metáforas de la vida cotidiana. Este modelo defiende que las metáforas constituyen un medio de crear, organizar y comprender la realidad, y van mucho más allá de establecer un punto de comparación más o menos ingenioso entre dos realidades. Así, partiendo de la idea de que el pensamiento humano está estructurado mediante asociaciones metafóricas que relacionan unos conceptos con otros, el usuario de la lengua, a fin de definir determinados conceptos, tiende a relacionarlos con sus experiencias más próximas con ayuda del lenguaje figurado (metafórico o metonímico), gracias al cual es capaz de conceptualizar esos elementos. Desde este punto de vista, Lakoff (1993: 203) entiende la metáfora como un conjunto de correspondencias de índole conceptual que nos permite definir y categorizar un concepto (el tabú de la muerte, en este caso) en términos de otra realidad más concreta y familiar. En suma, comprendemos aspectos de los conceptos en referencia a otros y, desde luego, los vínculos que se crean dicen mucho acerca del modo en el que el hablante entiende el concepto en cuestión. Bajo este enfoque, la metáfora se entiende como un recurso que estructura nuestro sistema conceptual, ofreciendo, al mismo tiempo, una particular percepción del mundo que nos rodea y una manera de dar sentido a nuestra experiencia. Por tanto, la metáfora se considera más que un tema puramente de lengua, como un modo de percibir la realidad, pensar y actuar:

[L]a metáfora se contempla característicamente como un rasgo sólo del lenguaje, cosa de palabras más que de pensamiento o acción. [...] Nosotros hemos llegado a la conclusión de que la metáfora, por el contrario, impregna la vida cotidiana, no solamente el lenguaje, sino también el pensamiento y la acción. Nuestro sistema conceptual ordinario, en términos 
del cual pensamos y actuamos, es fundamentalmente de naturaleza metafórica (Lakoff y Johnson 1986: 39).

Tomemos como ejemplo una conceptualización de la muerte muy habitual: MORIR ES DESCANSAR. En esta asociación conceptual tiene lugar una proyección desde la imagen de la que nos servimos para la categorización metafórica -o dominio fuente('descansar') al concepto que queremos metaforizar -o dominio término- ('morir'), y las asociaciones que constituyen esta metáfora configuran nuestra percepción de la muerte en términos de nuestro modo de entender un descanso. De hecho, la estructura cognitiva del dominio fuente permite categorizar el dominio término a partir de nuestra propia experiencia física o cultural. No es sino en esta correspondencia entre ambos dominios conceptuales donde la asociación cognitiva lleva a cabo la atenuación y, dependiendo del dominio fuente empleado en la categorización eufemística, estaremos conceptualizando el tabú de una u otra manera. El domino fuente es, por tanto, utilizado para entender, estructurar y, en casos como el propuesto, mitigar la referencia al hecho de la muerte. Como indican Chamizo Domínguez y Sánchez Benedito (2000: 75): "Los eufemismos pertenecen a nuestro sistema conceptual convencional y, según el tipo de eufemismo que escojamos para referirnos a un objeto tabú, lo estaremos conceptualizando de una determinada manera que diferirá de la manera de conceptualizar la misma realidad si escogemos cualquier otro eufemismo”. Y, lógicamente, la manera de conceptualizar un concepto tabú está íntimamente relacionada con el acervo cultural del usuario de la lengua.

Antes de pasar a la relación de metáforas conceptuales que actúan sobre el tabú de la muerte, delimitaré el concepto de eufemismo y el tipo de eufemismo que se adecua al marco teórico comentado. Siguiendo a Chamizo Domínguez y Sánchez Benedito (2000: 37), el eufemismo no es sino "el uso de un término en sentido traslaticio, esto es, conferir a un término, que tiene un significado literal tipificado por el uso de los hablantes, un significado distinto". Desde este punto de vista, estos autores consideran el eufemismo como un caso especial de metáfora, y como tal se ha de analizar. Para ello, me baso en la tipología de eufemismos metafóricos propuesta en un trabajo anterior (Crespo Fernández 2006b), basada a su vez en la ofrecida por Chamizo Domínguez y Sánchez Benedito (2000) ${ }^{4}$, en la que distingo entre eufemismos explícitos, convencionales, novedosos y estéticos. Concretamente, el tipo de eufemismo con el que se construyen las redes conceptuales es el eufemismo convencional, aquél cuya referencia velada al tabú se acepta de manera tácita por la comunidad de hablantes y mantiene intacto su poder de atenuación. Se trata de un eufemismo a medio camino entre los eufemismos novedoso y estético (impredecibles a priori con respecto al concepto tabú fuera de su contexto de preferencia) y el explícito (aquél que remite inequívocamente al concepto tabú al que sustituye, por lo que ha perdido su capacidad de mitigación). Así, la expresión descansar en el Señor (incluida en la metáfora MORIR ES DESCANSAR) se acepta convencionalmente como eufemismo de morir, por lo que

\footnotetext{
4 Chamizo Domínguez y Sánchez Benedito (2000: 68-70) distinguen tres tipos de eufemismos según su grado de lexicalización, es decir, según el grado en que los rasgos conceptuales del tabú se han adherido (y han contaminado) a los sustitutos eufemísticos: lexicalizados, semilexicalizados y novedosos o creativos. El eufemismo propio de la conceptualización metafórica, el eufemismo convencional, equivale, grosso modo, al que estos autores denominan lexicalizado.
} 
la referencia al tabú se identifica de inmediato, así como su voluntad de mitigación. Por el contrario, a la eterna región voló su alma en el ejemplo (7) precisa del contexto para la identificación del significado pretendido ('murió'), con lo que estamos ante un eufemismo novedoso y, dado el carácter poético y connotativo del que hace gala la ocultación del referente, estético ${ }^{5}$.

\section{El TABÚ DE LA MUERTE Y EL EUFEMISMO EN EL CORPUS}

El eufemismo que atañe a la muerte abunda en el corpus manejado. Aunque no es mi propósito en el presente artículo analizar los sustitutos no metafóricos del tabú, cabe destacar que en las 1253 inscripciones recopiladas he recogido 386 sustituciones léxicas para el concepto de 'morir' y 25 para 'muerto', mientras que los ortofemismos (principalmente morir y muerte) y disfemismos (como despojos) aparecen en 12 y 6 ocasiones respectivamente ${ }^{6}$. La fuerza y la vigencia del tabú de la muerte se observa igualmente en los 672 epitafios en los que el símbolo de la Cruz cristiana ( $\dagger$ ) sustituye a modo de eufemismo gráfico al verbo morir y, de manera más rotunda, en los 46 casos en los que se evita toda referencia al tabú, ni siquiera bajo atenuación eufemística. Por otra parte, el verbo más prolífico en la sustitución eufemística es el cultismo fallecer, del latín fallere 'faltar' (cf. Hernando 2001: 8), presente en 271 inscripciones en fosas y nichos. El siguiente gráfico muestra por porcentajes los distintos modos de representación del tabú de la muerte en el corpus:

Figura 1

El tabú de la muerte en el corpus

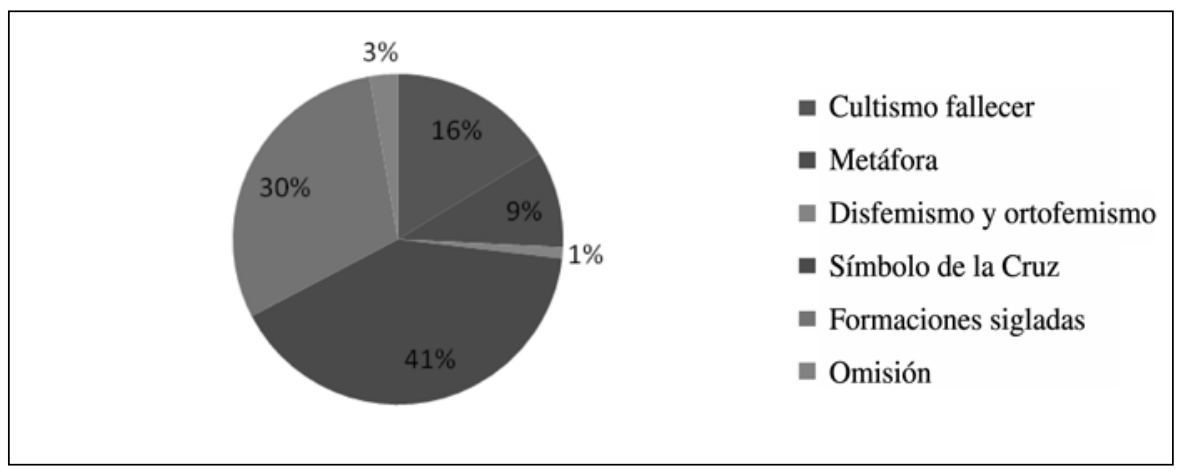

Como se aprecia en la figura, la metáfora juega un papel importante como proceso responsable de la sustitución léxica eufemística. De hecho, en el corpus manejado constituye el mecanismo de mayor capacidad lexicogenésica de eufemismos junto con el cultismo fallecer. La metáfora es responsable de 157 referencias eufemísticas, número

\footnotetext{
5 En relación con el eufemismo estético, véase Crespo Fernández (2007: 147-150).

${ }^{6}$ Entiendo por ortofemismo el término axiológicamente neutro o estrictamente referencial del concepto tabú, como es el caso de la palabra muerte (cf. Chamizo Domínguez 2004: 6). El disfemismo, sin embargo, amplifica los rasgos menos aceptables del referente que representa, como el término despojos para referirse a un cadáver.
} 
al que se podrían sumar los casos de formaciones sigladas como R.I.P. ('Requiescat in pace') y su equivalente en castellano D.E.P. ('Descanse en paz'), que se basan en la identificación de la muerte con un descanso y que aparecen en 497 inscripciones ${ }^{7}$, además de la frase ritual "no te olvida(n)", que, como explico más adelante, tiene su origen en la conceptualización MORIR ES VIVIR EN EL RECUERDO, y que está presente en 595 lápidas. En consecuencia, la metáfora es, en último extremo, responsable de un total de 1249 alternativas eufemísticas, lo que justifica sobradamente la presente investigación. A continuación analizo las distintas metáforas conceptuales que adopta el tabú de la muerte en el corpus.

\subsection{METAFORAS CONCEPTUALES EUFEMISTICAS}

Las sustituciones metafóricas del tabú de la muerte son susceptibles de ser analizadas según las categorizaciones conceptuales a las que los sustitutos eufemísticos pueden ser asignados. Concretamente, los eufemismos extraídos de los epitafios del corpus manejado se incluyen en seis metáforas conceptuales: MORIR ES DESCANSAR (48 sustituciones eufemísticas), MORIR ES SUBIR AL CIELo (42), MORIR ES VIVIR EN EL RECUERDO (35), MORIR ES CAER POR DIOS Y POR ESPAÑA (18), LA MUERTE ES UNA PÉRDIDA (10) Y LA MUERTE ES EL FINAL (4). El siguiente gráfico muestra la representación cuantitativa de cada una de estas metáforas en el corpus manejado:

Figura 2

Metáforas conceptuales eufemísticas en el corpus

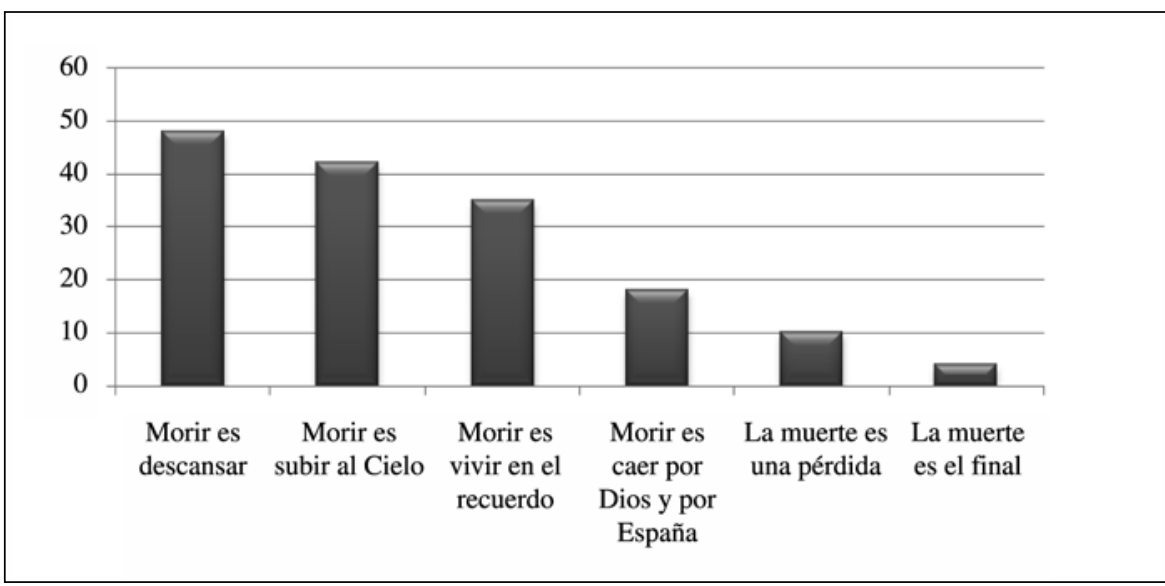

La mayoría de estas conceptualizaciones asocian la muerte a un hecho positivo. No en vano, en virtud de su base conceptual, cuatro de ellas implican, de una u otra manera, un juicio de valor positivo con respecto a la muerte. Tal es el caso de aquellas

\footnotetext{
${ }^{7}$ Sin embargo, no contabilizo las formaciones sigladas R.I.P y D.E.P. como sustituciones eufemísticas dentro de la metáfora LA MUERTE ES DESCANSO, ya que, al tratarse de fórmulas estandarizadas con un uso sumamente generalizado, contabilizarlas individualmente como eufemismos en esta conceptualización podría dar lugar a resultados engañosos. Lo mismo sucede con la expresión “... no te olvida(n)”, dentro de la metáfora MORIR ES VIVIR EN EL RECUERDO (cf. 4.1.3).
} 
que, motivadas por creencias religiosas, la consideran como una especie de recompensa en el Cielo después de la vida o, desde otros parámetros, como un servicio glorioso a la Patria. Sólo he observado dos asociaciones conceptuales con connotaciones negativas al presentar como dominios fuente una pérdida y el final de la existencia.

Es interesante destacar igualmente que algunas de estas conceptualizaciones metafóricas participan de otros recursos formativos. Tales son los casos de MORIR ES CAER POR DIOS Y POR ESPAÑA Y LA MUERTE ES UNA PÉRDIDA, que presentan una base conceptual metonímica ${ }^{8}$; MORIR ES VIVIR EN EL RECUERDO, que participa de la antífrasis por inversión del significado del verbo; y MORIR ES SUBIR AL CIELO, que presenta un matiz hiperbólico al magnificar el acto biológico de la muerte mediante su identificación con el traslado a la morada del Creador. El mismo tono grandilocuente se aprecia en MORIR ES CAER POR DIOS Y POR ESPAÑA, si bien en esta conceptualización la muerte se engrandece por motivos ideológicos y políticos. Sea como fuere, aunque estas categorizaciones conceptuales participan de otros mecanismos formativos, entiendo que presentan una base fundamentalmente metafórica, y así las considero en el presente trabajo.

\subsubsection{Morir es descansar}

La metáfora que considera la muerte en términos de un descanso es la más relevante en términos cuantitativos: está presente en un total de 48 epitafios del corpus, lo que supone poco más del $30 \%$ del total de eufemismos metafóricos observados. Este porcentaje se incrementaría notablemente si se incluyeran las formaciones sigladas D.E.P. y su equivalente latino R.I.P., aunque su extendidísimo uso hace perder conciencia de que su origen está en la asociación de la muerte a un descanso (véase la nota 7). Junto al verbo descansar, el más prolífico en la materialización léxica de esta metáfora, he encontrado yacer, reposar y dormir. Lo habitual de esta conceptualización en el corpus no debe extrañarnos; después de todo, la palabra cementerio tiene el significado de 'dormitorio' (cf. Chamizo Domínguez 2004: 49), por lo que, etimológicamente, el cementerio es el lugar donde el difunto está, sencillamente, en un plácido reposo. De ahí que esta identificación de la muerte con un descanso esté presente en la inscripción en latín de la entrada principal del camposanto de Albacete, por lo que, de alguna manera, parece acoger a todos los allí presentes ${ }^{9}$ :

\footnotetext{
8 Dada la delgada línea que separa a la metáfora de la metonimia en la conceptualización de conceptos abstractos (Goossens 1990: 332; Bultnick 1998: 62-72 y Barcelona 2003), en el presente trabajo he incluido, junto a las asociaciones conceptuales que presentan una base metafórica que se podría considerar "pura", las expresiones de lenguaje figurado con una base metonímica. Después de todo, la distinción tradicional entre metáfora y metonimia (i.e. la metáfora parte de una relación de semejanza entre un dominio fuente y un dominio término mientras que la metonimia establece una relación de contigüidad dentro de un único dominio por la que un aspecto del mismo representa su totalidad u otro aspecto) resulta, como defiende Bultnick (1998: 62), incapaz de dar cuenta de los matices semánticos que afectan a las expresiones del lenguaje figurado empleadas para designar la muerte, por lo que la división entre ambos recursos en algunas asociaciones conceptuales es más bien una cuestión de grado.

${ }^{9}$ En los ejemplos de epitafios del presente trabajo, he intentado respetar la presentación original de la fosa o nicho, lo que ha supuesto mantener la división de las líneas del texto o las faltas de ortografía existentes en el original.
} 


$$
\begin{gathered}
\text { Hic est locus ab eclesia } \\
\text { santificatus ubi quiescunt } \\
\text { qui resurrectionem spectant }{ }^{10}
\end{gathered}
$$

El verbo quiescunt ${ }^{11}$ 'descansan' establece el vínculo asociativo entre la muerte y un descanso, entendido éste como antesala de la resurrección, de la otra vida que espera a los difuntos, creencia que ayuda a sobrellevar la pena por el deceso de un ser querido y a disminuir el miedo a la muerte. Esta noción de descanso como paso previo a la resurrección implica que la muerte se considera indirectamente como un hecho transitorio, lo que constituye la base de la atenuación. Tal es el caso de la siguiente inscripción, en la que la muerte se conceptualiza como un descanso temporal:

$$
\begin{gathered}
\text { Manuela Montero Gualda } \\
\text { † 8-9-1939 a los } 72 \text { años } \\
\text { Descansa aquí } \\
\text { esperando resucitar }
\end{gathered}
$$

El carácter temporal del dominio fuente de esta metáfora supone, en último extremo, la negación de la muerte en sí: el difunto no está muerto, sino que descansa plácidamente, noción en la que se basa el consuelo de los familiares ${ }^{12}$. No sucede lo mismo en (3):

$$
\begin{gathered}
\text { Aquí descansan los restos de el } \mathrm{S}^{\mathrm{R}} \\
\text { D. Juan Dusac y Lopez } \\
\text { Fue alcalde de esta capital y médico } \\
\text { de la beneficencia municipal } \\
\text { Falleció el } 24 \text { de febrero } 1924 \\
\text { Su afligida viuda y desconsolados hijos } \\
\text { le dedican este recuerdo y piden } \\
\text { una piadosa oración por el } \\
\text { descanso eterno del alma del finado }
\end{gathered}
$$

Lejos de entender el descanso como temporal, los familiares admiten el carácter eterno del mismo, y por dicho descanso piden una oración, lo que demuestra que éste se considera como una recompensa en el más allá. De hecho, esta metáfora está vinculada a la idea de la muerte como condición deseable, como premio después de la experiencia terrenal, en la que el difunto finalmente logra un merecido reposo eterno, concepción basada en uno de los principales dogmas de las creencias cristianas tradicionales.

El descanso aparece matizado en ocasiones con expresiones del tipo "en paz", "en la paz del Señor" o "en el Señor”, lo que da idea del carácter espiritual del reposo en

\footnotetext{
10 "Este es el lugar santificado por la Iglesia donde descansan los que esperan la Resurrección".

11 Aries (cit. en Sexton 1997: 343) apunta como derivados con el significado de "aquí yace” o "aquí descansa" hic pausat, hic requiescit, hic dormit o requiescit in isto tumolo.

${ }^{12} \mathrm{La}$ asociación de la muerte a un descanso da lugar a situaciones verdaderamente rocambolescas. A título de curiosidad, según el testimonio de un enterrador recogido por Sexton (1997: 342), una mujer se negó a que su marido fuera enterrado al final del cementerio, pues había una carretera cerca y el ruido del tráfico podía molestarlo.
} 
cuestión y posibilita la inmediata asociación del descanso a la muerte, efecto que se consigue igualmente con adjetivos como eterno en (3). Esta matización del descanso en términos religiosos aparece en el siguiente epitafio de una religiosa:

$$
\begin{gathered}
\text { Madre María } \\
\text { Alemany Hernández } \\
\text { Cofundadora de la Institución } \\
\text { Presentacionista } \\
\text { descansó en la paz del Señor } \\
\text { el 28-5-1996 a los } 75 \text { años }
\end{gathered}
$$

Sin embargo, el descanso no siempre precisa de matizaciones léxicas para ser identificado con el hecho de fallecer; de hecho, las expresiones "aquí descansa(n)" o "aquí yace(n)" remiten de forma inequívoca a la muerte. Así sucede en (5):

\author{
Aquí yace el \\ Sr. D. Alberto Gómez Rey \\ y Almazán \\ Comandante de Caballería \\ que falleció el 23 de febrero de 1889 \\ a la edad de 39 años \\ Su esposa e hijos le dedican este recuerdo \\ R.I.P. \\ En definitiva, la conceptualización metafórica MORIR ES DESCANSAR está asociada \\ a un hecho tan familiar y placentero como es un descanso, descanso que se formula en \\ términos religiosos. La combinación de la experiencia física del descanso y del aspecto
} espiritual del mismo proporciona la base eufemística para abordar la muerte.

\title{
4.1.2. Morir es subir al Cielo
}

En relación con la metáfora recurrente en el lenguaje fúnebre que identifica la muerte con un viaje ${ }^{13}$, MORIR ES SUBIR AL CIELO se puede considerar como un traslado espiritual a la morada del Creador. Esta conceptualización se utiliza sistemáticamente para los epitafios de niños y bebés; de hecho, así sucede en las 42 ocasiones en las que aparece en las lápidas, lo que supone un $26,75 \%$ del total de sustituciones metafóricas del corpus. Veamos un ejemplo:

\footnotetext{
13 Aunque la metáfora LA MUERTE ES UN VIAJE no ha aparecido como tal en el corpus manejado para el presente trabajo, se trata de una asociación de ideas de carácter recurrente para abordar el hecho de la muerte, y su influencia se aprecia en conceptualizaciones eufemísticas como MORIR ES SUBIR AL CIELO y MORIR ES EL FINAL. Chamizo Domínguez y Sánchez Benedito (2000: 77) incluso entienden que la metáfora MORIR ES DESCANSAR está también indirectamente motivada por la metáfora muerte-viaje en tanto el fin del viaje significa el descanso para el viajero. Con respecto a esta conceptualización, véanse Bultnick (1998: 34-37) y Crespo Fernández (2006a: 114-117).
} 


\author{
Emilín Morales Gálvez \\ Subió al Cielo el 22 marzo 1961 \\ a los 2 años \\ Tus padres y hermanos \\ no te olvidan
}

Esta metáfora conceptualiza la mortalidad humana en términos de un dominio fuente con connotaciones positivas para el creyente, ya que la doctrina cristiana sitúa el reino de Dios en el Cielo, lo que otorga a esta asociación conceptual su fuerza mitigadora y su capacidad para el consuelo de los familiares del difunto, especialmente necesaria en el caso de la muerte de un niño, que se considera como una alteración de lo natural y moralmente correcto $^{14}$.

Concretamente, esta metáfora (al igual que LA MUERTE ES UN VIAJE) entiende que el difunto es quien emprende el trayecto y, por ello, se le considera, de alguna manera, todavía vivo, lo que se demuestra en el uso de verbos de movimiento como subir, ir y volar ${ }^{15}$. En consecuencia, al negar la ausencia de movimiento que conlleva la muerte, implícitamente se niega la muerte en sí, noción en la que se apoya también la fuerza eufemística de este dominio fuente. En el interesante ejemplo que sigue aparecen tres de las manifestaciones léxicas que adopta esta conceptualización metafórica: subió al cielo, voló su alma y fuiste al Cielo, expresiones que comparten la noción de movimiento:

\author{
Gertrudis López Cerdán \\ Subió al Cielo el 19 de enero de 1905 \\ a la edad de 13 años \\ Sus afligidos padres y hermanos \\ le dedican este recuerdo
}

\begin{abstract}
Murió la niña de hechiceros ojos y a la eterna región voló su alma ¡Feliz tú que por senda sin arrojos fuiste al Cielo mártir con la palma!
\end{abstract}

Las expresiones apuntadas, a las que cabe añadir subir a la Gloria, entienden la muerte como un viaje filtrado por creencias religiosas que tiene su destino en el encuentro con Dios en el Cielo. Según esta base conceptual, la muerte trasciende el hecho físico y adquiere tintes hiperbólicos al asociarse con la meta más elevada a la que todo cristiano debe aspirar. Esta conceptualización se basa pues en el ideal cristiano de la vida ultraterrena, por lo que guarda relación con LA MUERTE ES LA VIDA ETERNA, propuesta por Marín-Arrese (1996: 64).

\footnotetext{
${ }^{14}$ En algunas culturas las muertes de niños son especialmente dolorosas, pues se entiende que alteran el curso natural de la vida. Así, según apunta Barley (2000: 36-37), en Ghana, Madagascar o en el pueblo de los yoruba de Nigeria, los funerales de los ancianos celebran la plenitud de la vida del difunto y son motivo de alegría. Por el contrario, los funerales de los niños aparecen teñidos de dolor; no en vano, en Nigeria a los padres ni siquiera se les permite asistir al funeral de sus hijos.

15 La importancia del concepto de movimiento en esta metáfora es evidente. De hecho, Bultnick (1998: 34-38) incluye la conceptualización eufemística LA MUERTE ES UN VIAJE dentro de la más general LA MUERTE ES MOVIMIENTO.
} 


\subsubsection{Morir es vivir en el recuerdo}

La capacidad mitigadora de la metáfora MORIR ES VIVIR EN EL RECUERDO se vale del juego con la antítesis vivir/morir, al pretender igualar como modo de atenuación del tabú dos términos antitéticos. Esta antífrasis, presente en 35 inscripciones (22,29\% del total), se basa a su vez en la creencia religiosa de que morir es de alguna manera vivir, vida que, en este caso, implica estar presente en el recuerdo de los familiares del difunto, como en (8):

$$
\begin{gathered}
\text { Julián Martínez Rico } \\
\text { María López Parra } \\
\text { D.E.P. }
\end{gathered}
$$

Vivís en nuestro recuerdo

Esta categorización conceptual es igualmente responsable del encabezamiento "A la memoria de..." y de las fórmulas "Recuerdo de ..." y, sobre todo, “...no te olvida(n)", seguida y precedida respectivamente por el familiar o amigo en cuestión, que suelen finalizar el epitafio. En el siguiente ejemplo se combinan estas manifestaciones léxicas de la metáfora:

$$
\begin{aligned}
& \text { A la piadosa memoria de } \\
& \text { José Reales Martínez } \\
& \quad \nmid 2 \text {-XII-1967 } \\
& \text { Los tuyos no te olvidan }
\end{aligned}
$$

Dado que la promesa de no olvidar al difunto mediante la expresión ritual “... no te olvida(n)" responde a una inscripción estandarizada más que a cualquier voluntad eufemística, he optado por no contabilizarla, al igual que sucedía con las siglas D.E.P. y R.I.P. Baste decir que esta expresión se basa en la conceptualización que asocia la muerte con una vida en el recuerdo de los familiares y amigos, aunque debido a su uso tan generalizado se tiende a perder conciencia de su origen.

Por último, es interesante apuntar que la noción de la muerte como vida se encuentra también en el origen de ¡Presente!, voz utilizada en tres de las lápidas de aquellos que murieron en defensa del bando nacional en la Guerra Civil Española:

$$
\begin{gathered}
\text { Caído por Dios y } \\
\text { por España } \\
\text { Juan Muñoz Picón } \\
\text { ¡Presente! }
\end{gathered}
$$

La voz ¡Presente! sugiere que, de alguna manera, los que murieron por su Patria siguen entre los vivos, por lo que tiene lugar un eufemismo por inversión de significado. No sólo están vivos, sino dispuestos de nuevo, como en la inscripción anterior, a caer "por Dios y por España", aspecto que analizaré a continuación. 


\subsubsection{Morir es caer por Dios y por España}

La conceptualización MORIR ES CAER POR DIOS Y POR ESPAÑA tiene como objetivo enaltecer al muerto, por lo que presenta, como apunté anteriormente, tintes hiperbólicos. Se trata de una metáfora basada en la asociación metonímica LOS EFECTOS DE LA MUERTE REPRESENTAN LA MUERTE, en tanto identifica el hecho de morir con uno de sus efectos físicos, el de caer; así, la voz eufemística "caído" hace referencia en un sentido estricto al que cae desplomado a consecuencia de los disparos del enemigo. Se trata por tanto de una metáfora que precisa de una interpretación metonímica, y que Goossens (1990: 332) denomina "metáfora desde la metonimia".

Esta asociación conceptual considera al muerto como un caído por Dios y por España en 18 lápidas (11,46\% del total) de los partidarios y defensores tanto civiles como militares del bando nacional que murieron de forma violenta durante la Guerra Civil Española, que abarcó desde el 18 de julio de 1936 hasta abril de 1939. Dado que las muertes no sólo tuvieron lugar en el campo de batalla, la voz caído, como resultado de un proceso de generalización semántica, hace referencia en un sentido lato al que "cae" fusilado o sencillamente asesinado en la retaguardia ${ }^{16}$. Veamos un ejemplo:

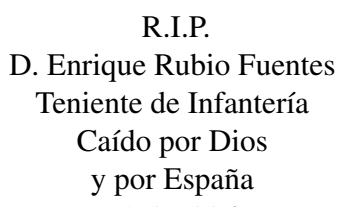

R.I.P.

D. Enrique Rubio Fuentes

Teniente de Infantería

Caído por Dios

y por España

12-8-1936

Este eufemismo conceptual, que supone toda una declaración de intenciones desde un punto de vista político, entiende que el difunto no murió en vano, sino que entregó su vida en defensa de Dios y de España durante una guerra en la que el enemigo marxista representaba para los partidarios del bando nacional tanto la ruptura de la unidad de la Patria como la negación de toda espiritualidad.

\subsubsection{La muerte es una pérdida}

La caracterización metafórica que asocia la muerte con una pérdida presenta, al igual que la anterior, una base metonímica, al basarse en los efectos de la muerte a través de la conceptualización metonímica LOS EFECTOS DE LA MUERTE REPRESENTAN LA MUERTE, lo que sucede en 10 ocasiones en el corpus (6,36\%). Según Bultnick (1998: 44-45), esta metáfora implica que la vida se considera el bien más preciado del ser humano y, por consiguiente, la muerte se entiende como la pérdida de dicho bien. Así, y contrariamente a lo que sucedía hasta ahora, se trata de una metáfora que conlleva una conceptualización de carácter negativo. De hecho, como indican Allan

\footnotetext{
${ }^{16}$ La represión durante la Guerra Civil Española fue atroz. El número de civiles fusilados tras juicios con mínimas garantías de imparcialidad o simplemente asesinados por simpatizar con el bando contrario fue elevadísimo, especialmente en los primeros meses de la guerra, periodo en el que el caos se apoderó del país. De hecho, en el corpus manejado todas las lápidas que consideran al muerto como "caído" datan desde finales de julio hasta septiembre de 1936, y sólo un caso corresponde a diciembre de ese mismo año. Con respecto a la violencia ejercida en la retaguardia en Albacete, consúltese Gómez Flores (2002: 73-79).
} 
y Burridge (1991: 62), la metáfora conceptual de la muerte-pérdida implica que la muerte escapa al control del ser humano, que queda indefenso ante su destino fatal, lo que parece evidente en el siguiente epitafio, especialmente emotivo:

$$
\begin{gathered}
\text { Maravillas del Moral Moraga } \\
\text { *16-10-1921 †1-2-2004 } \\
\text { De todas las penas madre } \\
\text { una, la más grande, la pena } \\
\text { negra. Pena de haberte } \\
\text { perdido madre. Ay qué pena! }
\end{gathered}
$$

Dentro de esta conceptualización, y con la misma motivación que la del apartado anterior, incluyo la expresión eufemística "dar la vida por Dios y por España”, sustitución del verbo morir en seis inscripciones del corpus. Veamos una de ellas:

$$
\begin{gathered}
\text { D. Fernando Alfaro Marín } \\
\text { dio su vida por Dios y por España } \\
\text { el } 26 \text { de agosto de } 1936 \\
\text { a los } 72 \text { años de edad } \\
\text { Recuerdo de su esposa e hijos }
\end{gathered}
$$

Comoquiera que la muerte supone la pérdida del don más preciado del ser humano, la vida, el "dar la vida por Dios y por España" se considera un acto de una generosidad sin límites, ya que este don se ofrece voluntariamente en defensa de un noble ideal, lo que constituye la base de atenuación de la expresión eufemística. Idéntica base conceptual, aunque carente de motivación política, se aprecia en eufemismos incluidos en esta metáfora del tipo "entregar el alma a Dios" o "el bien perdido" en referencia al difunto.

\subsubsection{La muerte es el final}

La conceptualización que identifica la muerte con el final de un periodo tiene escasa representación en el corpus manejado (cuatro sustituciones, que equivalen a poco más del 2,5\% del total). Esta metáfora se basa en la noción de que la vida es un proceso con un punto inicial, un punto final y una sucesión de tiempo entre ambos puntos, en virtud de un esquema configurado por los conceptos "fuente-camino-objetivo" que postuló Lakoff (1987: 275). Desde esta óptica, la muerte se conceptualiza como el final de un periodo, enfoque que permite la atenuación eufemística de la metáfora como el final del proceso de la vida humana, lo que sucede en (14):

$$
\begin{gathered}
\text { Hermenegildo García González } \\
\text { 16-XII-1902 nació } \\
\text { para hacer camino } \\
\text { 5-VII-1974 terminó su } \\
\text { camino hacia Dios }
\end{gathered}
$$

La sustitución eufemística de morir, "terminó su camino hacia Dios", se fundamenta en el encuentro con el Creador. En virtud de esta base conceptual, la vida se 
metaforiza con la imagen del camino que comienza en el nacimiento y finaliza el día de la muerte con el encuentro con Dios, por lo que el esquema configurado por los conceptos "fuente-camino-objetivo" se adapta para ser congruente con las creencias religiosas; no en vano, desde este punto de vista, se conceptualiza la muerte como el final de un viaje que tiene su punto de partida en el propio nacimiento y su destino en la reunión con el Todopoderoso.

La metáfora muerte-final tiene también su representación léxica, aunque desligada de toda connotación religiosa, en la voz culta finado, literalmente 'el que llega al fin de la vida':

$$
\begin{gathered}
\text { Juan Bautista Santonja } \\
\text { Rasón. Falleció el día } 10 \text { de } \\
\text { septiembre de } 1913
\end{gathered}
$$

La viuda del que aquí descansa eternamente y sus desconsolados hijos suplican en caridad una oración para el finado

En suma, los ejemplos anteriores, tanto con motivación religiosa o sin ella, temporalizan la muerte y la asocian al final de la existencia, conceptualización vinculada a la identificación de la vida en términos de un viaje y de la muerte como el fin de ese viaje (cf. nota 13).

\subsection{SUSTITUCIONES DEL TABU DE LA MUERTE EN DIACRONIA}

Junto al análisis de las metáforas conceptuales eufemísticas en el corpus manejado, merece la pena comentar el modo en el que tiene lugar la conceptualización eufemística del tabú de la muerte a lo largo de las épocas. En la siguiente tabla se refleja la representación cuantitativa de las distintas metáforas conceptuales, según la organización por zonas que señalaba en el apartado 2 del presente trabajo:

Tabla 1

Las metáforas conceptuales en diacronía

\begin{tabular}{|l|c|c|c|c|c|c|}
\cline { 2 - 7 } \multicolumn{1}{c|}{} & $\begin{array}{c}\text { morir es } \\
\text { descansar }\end{array}$ & $\begin{array}{c}\text { morir es } \\
\text { subir al } \\
\text { Cielo }\end{array}$ & $\begin{array}{c}\text { morir es } \\
\text { vivir en el } \\
\text { recuerdo }\end{array}$ & $\begin{array}{c}\text { morir es } \\
\text { caer por } \\
\text { Dios y } \\
\text { por España }\end{array}$ & $\begin{array}{c}\text { la muerte } \\
\text { es una } \\
\text { pérdida }\end{array}$ & $\begin{array}{c}\text { la muerte } \\
\text { es el final }\end{array}$ \\
\hline Zona 1 & 29 & 20 & 7 & 0 & 2 & 1 \\
\hline Zona 2 & 7 & 16 & 4 & 18 & 6 & 2 \\
\hline Zona 3 & 5 & 4 & 5 & 0 & 1 & 1 \\
\hline Zona 4 & 7 & 2 & 19 & 0 & 1 & 0 \\
\hline
\end{tabular}

Se aprecia que, en general, la presencia del eufemismo conceptual es inversamente proporcional al paso del tiempo, en consonancia con la preferencia por la alternativa léxica del tabú en las lápidas más antiguas, que se demuestra igualmente en otros medios de sustitución del tabú. Pongamos como ejemplo el cultismo fallecer (225 apariciones en las zonas 1-2 frente a sólo 16 en las zonas 3-4) y los disfemismos y 
ortofemismos (16 frente a dos). Así, no es de extrañar que el número de eufemismos metafóricos en los enterramientos anteriores a la década de los sesenta se eleve a 112, mientras que en las zonas 3-4 sea de tan sólo 45. Las dos conceptualizaciones con mayor representación cuantitativa siguen la misma pauta: MORIR ES DESCANSAR (36 sustituciones paliativas del tabú de la muerte en las zonas 1-2 y de 12 en las zonas 3-4) y MORIR ES SUBIR AL CIELO (36 eufemismos en las lápidas más antiguas frente a tan sólo seis desde la década de los sesenta), pauta que no varía en las de una menor presencia en el corpus, como la MUERTE ES UNA PÉRDIDA (ocho frente a dos). Otra conceptualización que carece de representación en las zonas 3-4 es MORIR ES CAER POR DIOS Y POR ESPAÑA, si bien en este caso no podía ser de otro modo, al referirse este eufemismo exclusivamente a los que murieron durante la Guerra Civil. La única categorización conceptual con más sustitutos a partir de la segunda mitad del siglo XX es MORIR ES VIVIR EN EL RECUERDO (11 en los enterramientos más antiguos frente a 24 en los recientes).

\section{CONCLUSIONES Y REFLEXIONES FINALES}

Siguiendo la fértil teoría de la Metáfora Conceptual propuesta por Lakoff y Johnson, he observado una gran variedad de asociaciones conceptuales en el lenguaje figurado eufemístico para el tabú de la muerte en el corpus de epitafios manejado. De hecho, la teoría cognitiva de la metáfora permite explicar el tratamiento léxico que recibe el tabú de la muerte; no en vano, el análisis de las diferentes metáforas conceptuales en las que se integran los sustitutos eufemísticos ofrece información de primera mano sobre el modo en el que este tabú se entiende, se percibe y, lo que es más importante en este artículo, se atenúa, en una prueba de que la comprensión de los procesos lingüísticos pasa por entender los procesos mentales.

Desde esta perspectiva, las sustituciones metafóricas observadas se agrupan en seis conceptualizaciones eufemísticas, a saber: MORIR ES DESCANSAR (30,57\% del total de la metaforización del corpus), MORIR ES SUBIR AL CIELO (26,75\%), MORIR ES VIVIR EN EL RECUERDO (22,29\%), MORIR ES CAER POR DIOS Y POR ESPAÑA (11,46\%), LA MUERTE ES UNA PÉRDIDA $(6,36 \%)$ y LA MUERTE ES EL FINAL $(2,54 \%)$. Cuatro de estas seis metáforas conceptuales consideran la muerte como un hecho deseable, lo que se aprecia en las connotaciones positivas de los dominios fuente, ya sea por motivos religiosos (los que mueren disfrutarán de una vida mejor en el Cielo junto al Creador), políticos (los fallecidos cumplen con un deber patriótico) o familiares (los difuntos viven en la memoria de los que quedan en este mundo). Aunque la naturaleza del dominio fuente en estas conceptualizaciones es radicalmente diferente del dominio término (el tabú de la muerte), la inmediata identificación de la referencia eufemística a la muerte se deriva del hecho de que estas asociaciones conceptuales forman parte del sistema cognitivo del receptor (cf. Lakoff 1993: 210) en cuanto a concepciones culturales de índole religiosa (la muerte supone otra vida junto a Dios en el Cielo) o político (la muerte como sacrificio por la Patria). De este modo, se supone que el finado evita un fallecimiento sin sentido, lo que, como señalan Allan y Burridge (1991: 159), constituye una de las principales causas del temor a la muerte entre los seres humanos. 
El análisis del eufemismo conceptual por distintas épocas llevado a cabo ha permitido, por otra parte, alcanzar resultados en diacronía sumamente reveladores de la conceptualización de la muerte en los epitafios. Conforme transcurren las décadas tiene lugar un acusado descenso de la metáfora como alternativa eufemística. Así, se puede afirmar que la metáfora constituye un recurso propio del sentimentalismo de épocas pasadas y poco común en la sociedad actual, momento en el que la referencia a la muerte en las lápidas -aunque paradójicamente en nuestros días se la llama menos por su nombre que en el pasado- raramente está impregnada de contenido metafórico.

En definitiva, el análisis de las inscripciones en lápidas del cementerio de una capital de provincias como Albacete en relación al eufemismo metafórico del tabú de la muerte ha revelado que el lenguaje figurado eufemístico responde a diferentes asociaciones conceptuales que suponen distintos modos de representar la muerte y conceptos afines. Más concretamente, en primer lugar, la destacada presencia de sustitutos metafóricos hasta aproximadamente la primera década del siglo XX revela un mayor sentimentalismo ante la muerte que en la época actual; en segundo lugar, la muerte se conceptualiza principalmente como un hecho deseable bajo la influencia de consideraciones religiosas basadas en el ideal cristiano de que la muerte supone un descanso en el Cielo, además de concepciones políticas y familiares, nociones que aportan la materia prima del eufemismo.

\section{OBRAS CITADAS}

Allan, Keith y Kate Burridge. 1991. Euphemism and Dysphemism: Language Used as Shield and Weapon. Oxford: Oxford University Press.

Barcelona, Antonio. 2003. "Clarifying and Applying the Notions of Metaphor and Metonymy Within Cognitive Linguistics: An Update". Metaphor and Metonymy in Comparison and Contrast. Eds. René Dirven y Ralf Pörings. Berlin: Mouton de Gruyter. 207-277.

Barley, Nigel. 2000. Bailando sobre la tumba. Barcelona: Anagrama.

Belmonte, Antonio. 1998. Muertos de papel. Albacete: La Mancha.

Bultnick, Bert. 1998. Metaphors We Die By: Conceptualizations of Death in English and their Implications for the Theory of Metaphor. Antwerpen: Universiteit Antwerpen.

Carandell, Luis. 1975. Tus amigos no te olvidan. Madrid: Maeva.

Casas Gómez, Miguel. 1986. La interdicción lingüística. Mecanismos del eufemismo y disfemismo. Cádiz: Universidad de Cádiz.

Chamizo Domínguez, Pedro. 2004. "La función social y cognitiva del eufemismo y del disfemismo". Panacea [Madrid] 5.15: 45-51.

_ y Francisco Sánchez Benedito. 2000. Lo que nunca se aprendió en clase. Eufemismos y disfemismos en el lenguaje erótico inglés. Granada: Comares.

Crespo Fernández, Eliecer. 2006a. "The Language of Death: Euphemism and Conceptual Metaphorization in Victorian Obituaries". SKY Journal of Linguistics [Helsinki] 19: 101-130.

2006b. "Metaphor in the Euphemistic Manipulation of the Taboo of Sex". Babel A.F.I.A.L. [Vigo] 15: 27-42.

—. 2007. El eufemismo y el disfemismo. Procesos de manipulación del tabú en el lenguaje literario inglés. Alicante: Publicaciones de la Universidad.

García-Sabell, Domingo. 1999. Paseo alrededor de la muerte. Madrid: Alianza. 
Gómez Flores, Andrés. 2002. La ciudad inventada. Albacete en la Guerra Civil. Albacete: Gráficas Ruiz.

Goossens, Louis. 1990. "Metaphtonimy. The Interaction of Metaphor and Metonymy in Figurative Expressions for Linguistic Action". Cognitive Linguistics 1.4: 323-340.

Gross, John. 1985. "Intimations of Mortality". Fair of Speech. The Uses of Euphemism. Ed. D. J. Enright. Oxford: Oxford University Press. 203-219.

Hernando, Bernardino. 2001. "La muerte mensajera. Las esquelas de defunción como elemento informativo". http: //www.ucm.es/info/perioI/Period_I/EMP/Numer_07/7.5-Inve/7-5-03.htm.

Hume, Janice. 2000. Obituaries in American Culture. Jackson: University Press of Mississippi.

Lakoff, George. 1987. Women, Fire and Dangerous Things. Chicago: The University of Chicago Press. 1993 [1979]. "The Contemporary Theory of Metaphor". Metaphor and Thought. Ed. Andrew Ortony. $2^{\mathrm{a}}$ ed. Cambridge: Cambridge University Press. 202-251.

— y Mark Johnson. 1986 [1980]. Metáforas de la vida cotidiana. Madrid: Cátedra.

Marín Arrese, Juana I. 1996. "To Die, to Sleep. A Contrastive Study of Metaphors for Death and Dying in English and Spanish". Language Sciences [Amsterdam] 18. 1-2: 37-52.

Moreno Fernández, Francisco. 1998. Principios de sociolingüística y sociología del lenguaje. Barcelona: Ariel.

Real Academia Española. 1992. Diccionario de la Lengua Española. 21ª ed. Madrid: Espasa Calpe.

Sexton, James. 1997. "The Semantics of Death and Dying: Metaphor and Mortality". A Review of General Semantics [Fort Worth, TX] 54. 3: 333-345. 